\title{
Harvesting Infrared Photons with Tricarbocyanine Dye Clusters
}

\author{
Kensuke Takechi ${ }^{a, \dagger}$, P. K. Sudeep ${ }^{a}$ and Prashant V. Kamat ${ }^{\star^{a, b}}$
}

${ }^{\mathrm{a}}$ Radiation Laboratory and ${ }^{\mathrm{b}}$ Departments of Chemistry and Biochemistry and Chemical \& Biomolecular Engineering

University of Notre Dame, Notre Dame, Indiana 46556-5674 


\section{Supporting Information}

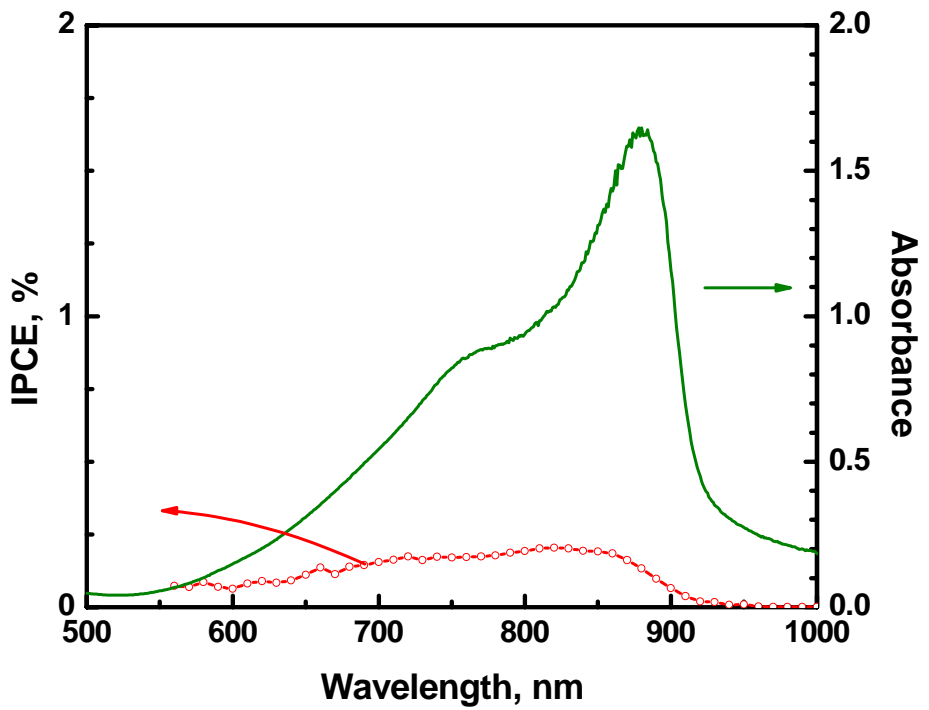

Figure S1. Absorption spectrum and incident photon to charge carrier generation efficiency (IPCE) of Jaggregated TCC dye film on OTE electrodes. The film was obtained by drop cast method from $1.5 \mathrm{mM} \mathrm{J}$ aggregated TCC dye aqueous solution. IPCE measurement was carried out in acetonitrile containing $\mathrm{I}^{-}$and $\mathrm{I}_{3}{ }^{-}$electrolyte. 